\title{
Short-Term Outcomes and Medical and Surgical Interventions in Infants with Congenital Diaphragmatic Hernia
}

Theresa R. Grover, MD ${ }^{1}$ Karna Murthy, MD²,* Beverly Brozanski, MD ${ }^{3} \quad$ Jason Gien, MD ${ }^{1}$ Natalie Rintoul, MD ${ }^{4}$ Sarah Keene, MD $^{5}$ Tasnim Najaf, MD ${ }^{6}$ Louis Chicoine, MD Nicolas Porta, MD ${ }^{2}$ Isabella Zaniletti, $\mathrm{PhD}^{8}$ Eugenia K. Pallotto, $\mathrm{MD}^{9, *}$ and the Children's Hospitals Neonatal Consortium*

${ }^{1}$ Children's Hospital Colorado and University of Colorado School of Address for correspondence Theresa R. Grover, MD, University of Medicine, Aurora, Colorado

${ }^{2}$ Ann and Robert H. Lurie Children's Hospital and Feinberg School of Colorado School of Medicine, 13121 E. 17th Avenue, MS 8402, Aurora, Medicine, Northwestern University, Chicago, Illinois

${ }^{3}$ Children's Hospital of Pittsburgh and University of Pittsburgh School CO 80045 (e-mail: theresa.grover@childrenscolorado.org).

of Medicine, Pittsburgh, Pennsylvania

${ }^{4}$ Children's Hospital of Philadelphia and University of Pennsylvania

School of Medicine, Philadelphia, Pennsylvania

${ }^{5}$ Children's Healthcare of Atlanta and Emory University School of

Medicine, Atlanta, Georgia

${ }^{6}$ Washington University, St. Louis, Missouri

${ }^{7}$ Nationwide Children's Hospital, Columbus, Ohio

${ }^{8}$ Children's Hospital Association, Overland Park, Kansas

${ }^{9}$ Children's Mercy Hospital and University of Missouri, Kansas City, Missouri Am J Perinatol 2015;32:1038-1044.

\author{
Abstract \\ Keywords \\ - congenital \\ diaphragmatic hernia \\ - neonatal \\ - pulmonary \\ hypertension \\ - prematurity \\ - NICU \\ - pulmonary hypoplasia \\ - respiratory failure
}

Objective The aim of this study is to characterize medical and surgical therapies and short-term outcomes in infants with congenital diaphragmatic hernia (CDH).

Study Design Retrospective analysis of CDH infants admitted to 27 children's hospitals submitting data to Children's Hospital Neonatal Database (CHND) from 2010 to 2013, stratified by gestational age, birth weight, and survival.

Results A total of 572 infants were identified, 508 (89\%) born $\geq 34$ weeks' gestation and $\geq 2 \mathrm{~kg}$. More mature infants had higher APGAR scores, shorter duration of mechanical ventilation, and were more likely to receive extracorporeal membrane oxygenation (ECMO). Overall, mortality for the cohort was $29 \%$, with mortality lower in infants born $\geq 34$ weeks' gestation and $\geq 2 \mathrm{~kg}$ ( 26 vs. $50 \%, p<0.01)$. Nonsurvivors were more likely to receive treatment with high-frequency oscillatory ventilation (HFOV), vasopressors, pulmonary vasodilators, and ECMO, and to have associated major congenital anomalies than survivors. In hospital morbidity and complications were relatively uncommon among survivors.

Conclusion Infants with $\mathrm{CDH}$ have a high risk of morbidity and mortality, and for preterm infants with $\mathrm{CDH}$ those risks are amplified. Patterns of respiratory and circulatory support appeared to be different for survivors. In addition to established data registries, this consortium of regional neonatal intensive care units provides a new collaborative effort to describe short-term outcomes for infants referred with $\mathrm{CDH}$.

\footnotetext{
Michael A Padula, Jeanette M Asselin, David J Durand, Billie L Short Francine D Dykes, Kristina M Reber, and Jacquelyn R Evans.
}

received

October 14, 2014

accepted after revision

January 20, 2015

published online

March 31, 2015
Copyright $\odot 2015$ by Thieme Medical Publishers, Inc., 333 Seventh Avenue, New York, NY 10001, USA. Tel: +1(212) 584-4662.
DOI http://dx.doi.org/ 10.1055/s-0035-1548729. ISSN 0735-1631. 
Congenital diaphragmatic hernia $(\mathrm{CDH})$ is a life-threatening anomaly occurring in 1 of every 3,000 to 5,000 live births. It is associated with respiratory failure, pulmonary hypoplasia, pulmonary hypertension, and mortality ranging from 24 to $40 \%{ }^{1-4}$ International groups have studied these infants from both a medical and surgical perspective, 5,6 and many shortterm outcomes have been previously defined. ${ }^{7}$ Although some risk factors for mortality have been described, ${ }^{8}$ early prediction of mortality and other morbidities remains a challenge. $^{9-11}$

Most neonatal intensive care units (NICUs) have few patients with $\mathrm{CDH} .{ }^{12,13}$ Even in the regional NICU that cares for infants referred with $\mathrm{CDH}$, patient accrual is insufficient to adequately describe patient characteristics, the distribution of applied therapies, or short-term outcomes over a contemporary period. ${ }^{14}$ Longitudinal single-center reports are difficult to interpret as institutional practice and technologic advances vary over time, making the use of historic controls fraught with bias. Detailed description of infants with CDH in a contemporary, multi-institutional cohort is a necessary step to associate risk factors with patient outcomes. Moreover, a traditional focus on the surgical procedures has left the exploration of the risks and benefits of the applied medical therapies less well defined.

Using an extensive clinical data set of infants referred to participating regional NICUs, we focused this report on the characterization of infants with $\mathrm{CDH}$ and their in-hospital outcomes for a large, multicenter contemporary cohort in the United States. Because infants born less than 34 weeks' gestation have a higher risk or mortality and are typically not considered candidates for therapies such as extracorporeal membrane oxygenation (ECMO), we stratified the analysis of medical and surgical inventions and outcomes by gestational age (GA) and birth weight (BW).

\section{Patients and Methods}

The Children's Hospital Neonatal Database (CHND) captures clinical data on all infants admitted to 27 participating regional NICUs. ${ }^{13}$ For this study, all infants with a diagnosis of CDH over a 4-year period (2010-2013) were identified. Infants who had surgical repair before referral or had previously been discharged home were not included in this analysis. The cohort included patients from 22 of 27 hospitals who contributed expanded data focused on $\mathrm{CDH}$ patients; thus, patients from the remaining five hospitals that did not participate in the $\mathrm{CDH}$ module were prospectively excluded $(n=49)$. Chart abstractors at each site completed prospective training including review of clinical definitions, participation in web-based seminar tutorials, and case-based practice. ${ }^{13}$ The Stanley Manne Children's Research Institute's Institutional Review Board (Chicago, Illinois) approved this analysis (\#2011-14673), and each participating site has ongoing local institutional review board approval for participation in the data registry.

Eligible infants were described using maternal and infant demographic, birth, and clinical characteristics including selected variables that occurred before referral to the regional
NICU. These were reported for the whole cohort and after stratification: those born $<34$ weeks' gestation or $<2 \mathrm{~kg}$ (cohort 1 ) and those born $\geq 34$ weeks' gestation and $\geq 2 \mathrm{~kg}$ (cohort 2). These groups were chosen to isolate the larger, more mature infants who may have been eligible candidates to receive ECMO. ${ }^{15}$

The characteristics of the type of defect, type of repair, surgical approach, and distribution of selected perioperative sequelae were reported. Clinical interventions provided were described, including respiratory and vasopressor support, and receipt of ECMO or pulmonary vasodilator medications. For these variables, the cohort was stratified by mortality to demonstrate the unadjusted differences in the receipt of therapies.

The outcomes described are those achieved before hospital discharge from the regional NICU. Some infants were transferred to another institution, and data on the final disposition of these infants were not measured systematically. The prevalence of other selected morbidities including the prevalence of central line associated blood stream infections, duration of mechanical ventilation, and hospital length of stay (LOS) are reported for the duration of stay within the participating CHND hospitals.

Data description and analyses were performed with SAS v9.3 (Cary, NC). Student $t$-test, chi-squared, and bivariable analyses were applied, as appropriate. Nonparametric testing was applied when the distribution of selected measures did not conform to a normal distribution.

\section{Results}

Of the 49,403 records in CHND, 642 infants (1.4\%) had a diagnosis of $\mathrm{CDH}$ for their first admission to these participating regional NICUs. After excluding infants with incomplete data $(n=49)$ and those who were repaired $(n=3)$ or previously home before referral $(n=18), 572$ infants with $\mathrm{CDH}$ were eligible for analysis. Patient volume varied by center (median, 23 patients per center; [inter-quartile range, IQR, 10, 34]), and six centers had more than $36 \mathrm{CDH}$ patients included.

\section{Prenatal and Perinatal Characteristics}

Prenatal diagnosis was made in $64 \%$ of $\mathrm{CDH}$ patients, and most infants (89\%) were born $\geq 34$ weeks' gestation and $\geq 2$ $\mathrm{kg}$ (cohort 2). Small for GA, ${ }^{16}$ multiple gestation, cesarean delivery, antenatal steroid administration, APGAR scores $\leq 5$ at 1,5 , or 10 minutes, and exogenous surfactant therapy before referral were more frequently observed in cohort 1 compared with those in cohort 2 (-Table 1). Infants were referred early after birth (median, 3.6 hours; IQR, 1.5, 6.3 hours) and $89 \%$ were referred before 24 hours of age. Only one infant at any gestation had confirmed sepsis present at the time of referral.

\section{Congenital Diaphragmatic Hernia Defect and Operative Repair}

Characteristics of the diaphragmatic hernia itself were recorded among those who were surgically repaired ( $n=450$; 78.6\% of $\mathrm{CDH}$ patients). Right-sided defects were more 
Table 1 Demographic variables associated with $\mathrm{CDH}$ patients referred to CHND NICUs

\begin{tabular}{|c|c|c|c|c|}
\hline \multirow[t]{2}{*}{ Variable } & \multirow[t]{2}{*}{ All } & \multicolumn{2}{|l|}{ GA/BW stratification } & \multirow[t]{2}{*}{$p$ Value } \\
\hline & & $<34$ wks or $<2 \mathrm{~kg}$ & $\geq 34$ wks and $>2 \mathrm{~kg}$ & \\
\hline Number of $\mathrm{CDH}$ patients & 572 & $64(11)$ & $508(89)$ & \\
\hline Median GA in weeks (IQR) & $38(36,39)$ & $32(31,33)$ & $38(37,39)$ & $<0.001$ \\
\hline Median BW in grams (IQR) & $3,000(2,580,3,345)$ & $1,777(1,438,1,970)$ & $3,068(2,745,3,400)$ & $<0.001$ \\
\hline SGA (< 10\%ile) & $68(12)$ & $14(22)$ & $54(11)$ & 0.014 \\
\hline Multiple gestations & $23(4)$ & $8(13)$ & $15(3)$ & 0.002 \\
\hline Cesarean delivery & $256(45)$ & $42(66)$ & $214(42)$ & 0.001 \\
\hline Antenatal steroids & $65(11)$ & $26(41)$ & $39(8)$ & $<0.001$ \\
\hline APGAR @1 minute $\leq 5$ & $333(58)$ & $47(73)$ & $286(56)$ & 0.004 \\
\hline APGAR @5 minute $\leq 5$ & $142(25)$ & $26(41)$ & $116(23)$ & 0.007 \\
\hline APGAR @10 minute $\leq 5$ & $55(10)$ & $11(17)$ & $44(9)$ & 0.005 \\
\hline Surfactant before referral & $90(16)$ & $33(52)$ & $57(11)$ & $<0.001$ \\
\hline
\end{tabular}

Abbreviations: BW, birth weight; $\mathrm{CDH}$, congenital diaphragmatic hernia; GA, gestational age; IQR, interquartile range; SGA, small for gestational age. Note: Using published gender-specific and gestational age-specific normative values. ${ }^{8}$ Data presented are $N$ (\%) or median (IQR).

common in cohort 1 (28.2 vs. $14.8 \%, p=0.028$ ) as was liver herniation into the thorax ( 61.5 vs. $47.5 \%, p=0.002$ ). In contrast, thoracostomy tubes were more frequently placed in the larger, more mature infants ( 45.5 vs. $28.2 \% ; p=0.043$ ), although most were on the side ipsilateral to the defect and placed after $\mathrm{CDH}$ repair (84\%). In both the strata, the majority of infants received surgical repair in the first (49\%) or second (26\%) weeks of life, with a median age at repair of 7 days $(\mathrm{IQR}=3,13)$. Most operative repairs occurred in the operating room (62\%) rather than in the NICU (38\%). Patch (51\%) and primary $(47 \%)$ repairs were divided equally among infants, and were similar in frequency in both strata $(p=0.66)$. Patch repair was associated with an increased risk for mortality relative to primary repair ( 12 vs. $1.3 \%, p<0.01$ ) as was need for thoracostomy tube on either the ipsilateral or contralateral side before surgical repair $(p<0.0001)$. Of those infants who were surgically repaired, $11 \%(n=52)$ received an operative repair while receiving ECMO. Complications after operative repair were infrequent with postoperative chylothorax (6.4\%), liver/splenic laceration (2.9\%), and recurrent hernia before discharge (2.4\%) noted as the three most common problems. Infections, postoperative hemorrhage, intestinal ischemia/injury, and abdominal compartment syndrome were reported as singular events in the entire cohort. Complications were similar by GA and BW strata.

\section{Medical Therapies Provided during Hospitalization}

$\mathrm{CDH}$ infants received complex medical support during their NICU hospitalization (-Table 2). Infants were typically intubated on their day of birth (94\%), and both mechanical ventilation and noninvasive respiratory supports were nearly universally applied with few differences between the GA/BW strata. Infants in cohort 1 were treated less commonly with conventional mechanical ventilation than those in cohort 2 , although use of high-frequency oscillatory ventilation (HFOV) was similar between the groups. For those infants receiving mechanical ventilation, the total duration of respiratory support was longer in the preterm cohort. Not surprisingly, preterm infants were less likely to receive ECMO, but for those treated, the median duration of ECMO therapy was significantly longer (cohort 1: 19 days vs. cohort 2: 11 days; $p=0.04$ ), and survival after ECMO trended lower (cohort $1=17$ vs. cohort $2=52 \% ; p=0.11$ ). Vasopressors and pulmonary vasodilator medications were frequently used; of note, inhaled nitric oxide was used in the majority (62\%) of infants and $22 \%$ received sildenafil.

\section{Mortality}

Overall mortality was $29 \%$; preterm infants had a mortality rate of $50 \%$, compared with $27 \%$ for infants in cohort 2 $(p<0.001)$ ( - Table 3). Prenatal diagnosis of $\mathrm{CDH}$ was more frequently made in nonsurviving infants (77 vs. $59 \%$; $p<0.001$ ). Mortality associated with ECMO use was 49\% compared with $20 \%$ in those who did not receive ECMO $(p<0.001)$. Nonsurviving infants were less likely to receive conventional mechanical ventilation, and more likely to be treated with high-frequency mechanical ventilation (-Table 4). Only seven infants in the entire cohort did not receive mechanical ventilation outside the immediate perioperative period, and one was a nonsurvivor. Vasopressor and prostanoid medications as well as ECMO were used more frequently among nonsurvivors, and the median duration of ECMO was longer than in survivors (14.3 vs. 8.6 days, $p<0.001$ ). Associated major congenital anomalies (cardiac, genetic syndrome, and other major anomalies) were more frequent in nonsurviving infants ( $41 \mathrm{vs.} 27 \% ; p=0.008$ ). The recorded causes of death were related to pulmonary hypoplasia, pulmonary hypertension, and/or cardiopulmonary failure in all but 10 patients. For these 10 patients, their cause of death was related to hemorrhage $(n=2)$, brain injury $(n=6)$, vascular dissection $(n=1)$, and thrombosis $(n=1)$. 
Table 2 Respiratory support during CDH hospitalization, stratified by gestational age and birth weight

\begin{tabular}{|c|c|c|c|c|}
\hline VARIABLE & ALL, $(N=572)$ & $\begin{array}{l}<34 \text { wks or }<2 \mathrm{~kg} \\
(n=64)\end{array}$ & $\begin{array}{l}\geq 34 \mathrm{wks} \text { and } \\
>2 \mathrm{~kg}(n=508)\end{array}$ & $p$ Value \\
\hline \multicolumn{5}{|l|}{ Advanced respiratory support } \\
\hline Median days on respiratory support (median, IQR) & $18(10,38)$ & $46(13,74)$ & $18(10,36)$ & 0.039 \\
\hline Median days on mechanical ventilation & $15(6,29)$ & $17(5,38)$ & $15(6,28)$ & 0.735 \\
\hline High-frequency oscillatory ventilation, $N(\%)$ & $225(39)$ & $23(36)$ & $202(40)$ & 0.590 \\
\hline Median duration in days & $5(2,13)$ & $7(2,19)$ & $5(2,13)$ & 0.214 \\
\hline Conventional ventilation & $510(89)$ & $50(78)$ & $460(91)$ & 0.005 \\
\hline Median duration in days & $12(5,23)$ & $14(3,47)$ & $12(5,22)$ & 0.366 \\
\hline \multicolumn{5}{|l|}{ Vasopressors } \\
\hline Dopamine & $419(73)$ & $50(78)$ & $369(73)$ & 0.454 \\
\hline Epinephrine & $192(34)$ & $23(36)$ & $169(33)$ & 0.675 \\
\hline Milrinone & $172(30)$ & $17(27)$ & $155(31)$ & 0.565 \\
\hline Dobutamine & $76(13)$ & $12(19)$ & $64(13)$ & 0.173 \\
\hline Vasopressin & $30(5)$ & $4(6)$ & $26(5)$ & 0.764 \\
\hline Norepinephrine & $15(3)$ & $1(1.5)$ & $14(3)$ & 1.000 \\
\hline \multicolumn{5}{|l|}{ Vasodilators } \\
\hline Inhaled nitric oxide & $353(62)$ & $39(61)$ & $314(62)$ & 0.892 \\
\hline Sildenafil & $126(22)$ & $12(19)$ & $114(22)$ & 0.631 \\
\hline Prostaglandin E1 & $37(6)$ & $4(6)$ & $33(7)$ & 1.000 \\
\hline Prostacyclin & $19(3)$ & $1(1.5)$ & $18(4)$ & 0.711 \\
\hline Bosentan & $12(2)$ & $0(0)$ & $12(2)$ & 0.378 \\
\hline ECMO & $186(33)$ & $6(9)$ & $180(35)$ & $<0.001$ \\
\hline Total days on ECMO & $11(7,18)$ & $19(15,37)$ & $11(7,17)$ & 0.037 \\
\hline
\end{tabular}

Abbreviations: $\mathrm{CDH}$, congenital diaphragmatic hernia; $\mathrm{ECMO}$, extracorporeal membrane oxygenation.

Note: Data presented are $n(\%)$ or median, (interquartile range).

\section{Additional Short-Term Outcome Metrics}

Median hospital LOS was 32 days (IQR 16, 66 days), and correspondingly, $11 \%$ of CDH infants had an LOS in excess of 90 days. The use and duration of central venous lines were both frequent (mean of 2 central lines per patient) and prolonged (mean of 20 days per patient), and $9 \%$ developed a blood stream infection during their hospitalization. A brain injury was documented on imaging studies in $1.6 \%$ of patients, and $19 \mathrm{CDH}$ patients were treated with therapeutic hypothermia for hypoxic-ischemic encephalopathy, of which 10 patients survived. Seizures were common (7.3\%) and 3.7\% were diagnosed with hearing deficits before discharge. The pharmacologic treatment of gastroesophageal reflux was nearly universal (99.3\% of CDH patients), although surgical fundoplication was infrequent (8.1\%). Preterm infants were discharged home with supplemental oxygen, diuretic medications, and tube feedings more frequently than infants born near or full term ( - Table 3$)$.

\section{Discussion}

Despite recent advances in medical technology and care, infants with CDH experience significant morbidity and mor- tality. ${ }^{1-4}$ Several groups have examined the management of $\mathrm{CDH}$ as well as for identification of factors that predict outcome. ${ }^{5-11}$ We describe a large multicenter cohort of $\mathrm{CDH}$ infants referred to regional NICUs for care with an emphasis on the medical therapy provided because these therapies in a large contemporary cohort have not been well described. Better understanding of the variability in practice and center-specific practices as they relate to outcome may ultimately help to identify best practices that may improve outcomes for affected infants.

Although prematurity has been identified as an independent predictor of adverse outcomes in $\mathrm{CDH},{ }^{17,18}$ relatively few studies have examined this group of $\mathrm{CDH}$ patients in detail. Our cohort shows that infants born $<34$ weeks' gestation or $<2 \mathrm{~kg}$ in weight are as likely to receive aggressive care as more mature infants, with the exception of ECMO. Overall, the preterm, smaller infants received respiratory support and ECMO therapy for a longer duration. We also found that $\mathrm{CDH}$ infants born prematurely more commonly had a right-sided $\mathrm{CDH}$, and previous reports have shown that these infants are more likely to have associated anomalies ${ }^{17}$; both risk factors associated with mortality. ${ }^{7,19,20}$ Clearly, preterm infants with $\mathrm{CDH}$ represent an 
Table 3 Predischarge outcomes in infants with $\mathrm{CDH}$

\begin{tabular}{|c|c|c|c|c|}
\hline Variable & All $(N=572)$ & $<34$ wk or $<2 \mathrm{~kg}(n=64)$ & $\begin{array}{l}\geq 34 \text { wk and } \geq 2 \mathrm{~kg} \\
(n=508)\end{array}$ & $p$ Value \\
\hline Mortality, $n(\%)$ & $167(29)$ & $32(50)$ & $135(27)$ & $<0.001$ \\
\hline Median hospital length of stay (IQR) & $32(16,66)$ & $40(5,76)$ & $32(17,63)$ & 0.890 \\
\hline $\mathrm{CDH}$ patients discharged home & $356(66)$ & $21(33)$ & $352(69)$ & \\
\hline \multicolumn{5}{|l|}{ Route of feed at discharge } \\
\hline Breast & $139(40)$ & $6(29)$ & $133(41)$ & 0.259 \\
\hline Bottle & $255(74)$ & $15(71)$ & $240(74)$ & 0.789 \\
\hline Tube $^{a}$ & $142(41)$ & $15(71)$ & $127(39)$ & 0.004 \\
\hline Bottle and tube ${ }^{a}$ & $73(21)$ & $9(43)$ & $64(20)$ & 0.012 \\
\hline \multicolumn{5}{|l|}{ Discharge medications } \\
\hline Supplemental oxygen & $83(24)$ & $10(48)$ & $73(23)$ & 0.009 \\
\hline Sildenafil & $47(14)$ & $5(24)$ & $42(13)$ & 0.158 \\
\hline Furosemide & $24(7)$ & $5(24)$ & $19(6)$ & 0.002 \\
\hline Thiazide & $22(6)$ & 4 (19) & $18(6)$ & 0.036 \\
\hline
\end{tabular}

Abbreviation: $\mathrm{CDH}$, congenital diaphragmatic hernia.

ancludes gastrostomy, nasogastric, or transpyloric administration of feedings. Data presented are $n$ (\%) or median (interquartile range).

extremely high-risk group of patients, with a higher morbidity and mortality than more mature infants.

In our cohort, the survival of preterm infants was $50 \%$, which included one infant treated with ECMO. For those preterm infants who survived, more were discharged on oxygen or with feeding assistance than mature infants, but with comparable rates of documented brain injury, seizures, and hearing loss. Although increased risk of long-term morbidity must be considered in this population, counseling and overall approach to care of preterm infants with $\mathrm{CDH}$ should balance this risk with the likelihood of short-term survivaland the burdens of lengthy hospitalizations-when considering aggressive treatment.

Overall survival in this group of patients referred for care of $\mathrm{CDH}$ was $71 \%$, similar to that in previous reports. ${ }^{1,4,10,12}$ As expected, the majority of nonsurvivors died as a result of pulmonary hypoplasia, pulmonary hypertension, and cardiopulmonary failure. Nonsurvivors were treated with more medical therapies including HFOV, vasopressors, pulmonary vasodilator medications, and ECMO despite uncertain efficacy to increase the likelihood of survival. Interestingly, we did find that after referral to regional NICUs, only a single nonsurvivor was not mechanically ventilated, suggesting that these infants are nearly universally offered aggressive intervention. Despite this, mortality remains high for this condition. Continued efforts to define those infants least likely to respond to aggressive medical and surgical intervention are warranted.

Despite a high risk of morbidity related to treatment of $\mathrm{CDH}$, we found that in-hospital outcomes for survivors were relatively favorable. Specifically, surgical, infectious, and neurologic complications existed, but they were infrequent, and the majority of patients were discharged home without supplemental oxygen or medications to treat pulmonary hypertension. This cohort of infants was treated with many medical therapies, for which evidence is limited or incomplete, including inhaled nitric oxide, sildenafil, diuretic medications, and acid suppression medications for gastroesophageal reflux during their initial hospital course. $^{19-26}$ Use of this data in conjunction with additional prospective studies may help to determine most effective practices for medical management of $\mathrm{CDH}$.

There are limitations of this study that surround the issue of referral bias. This cohort referred to regional NICUs may not be representative of the entire population of infants with $\mathrm{CDH}$; it is plausible that the infants who were most likely to experience complications or poor outcomes associated with $\mathrm{CDH}$ were referred to these NICUs. Alternatively, infants deemed as nonsurvivable, whether term or preterm, may have remained at the referral hospital and not transferred for aggressive care. Nevertheless, this report summarizes the therapies received and the short-term outcomes of a large, contemporary, US-born cohort of infants with CDH referred to participating children's hospitals' NICUs to provide data for counseling families of affected infants.

In summary, these results facilitate a greater understanding of the burden $\mathrm{CDH}$ infants face, both for clinicians and for families of affected infants. Although individual hypotheses were not tested, these data serve to generate hypotheses on which future prediction and prospective studies will be based. Moreover, these results demonstrate the successful collaboration between 27 hospitals in the United States focused on high-risk infants with complex diseases and rare conditions. Specifically, these data provide the framework for future studies to predict short-term outcomes using clinical risk factors as well as to quantify the intercenter variation in care delivered and outcomes achieved between these regional NICUs. 
Table 4 Therapies utilized by CDH patients during initial hospitalization

\begin{tabular}{|c|c|c|c|c|}
\hline Variable & All $(N=572)$ & $\begin{array}{l}\text { Survivors } \\
(n=405)\end{array}$ & $\begin{array}{l}\text { Nonsurvivors } \\
(n=167)\end{array}$ & $p$ Value \\
\hline \multicolumn{5}{|l|}{ Advanced respiratory support } \\
\hline Median days on mechanical ventilation (median, IQR) & $15(6,29)$ & $15(7,29)$ & $15.5(2,27)$ & 0.013 \\
\hline High frequency oscillatory ventilation, $N(\%)$ & $347(61)$ & $199(49)$ & $148(89)$ & $<0.001$ \\
\hline Median duration in days & $5(2,13)$ & $6(2,13)$ & $3.5(1,14)$ & 0.039 \\
\hline High-frequency jet ventilation & $11(2)$ & $6(1.5)$ & $5(3)$ & 0.31 \\
\hline Median duration in days & $4(1,9)$ & $2(1,4)$ & $9(6,15)$ & 0.016 \\
\hline Conventional ventilation & $510(89)$ & $385(95)$ & $125(75)$ & $<0.001$ \\
\hline Median duration in days & $12(5,23)$ & $12(6,23)$ & $10(3,22)$ & 0.009 \\
\hline \multicolumn{5}{|l|}{ Vasopressors } \\
\hline Dopamine & $419(73)$ & $271(67)$ & $148(89)$ & $<0.001$ \\
\hline Epinephrine & $192(34)$ & $103(25)$ & $89(53)$ & $<0.001$ \\
\hline Milrinone & $172(30)$ & $91(22)$ & $81(49)$ & $<0.001$ \\
\hline Dobutamine & $76(13)$ & $36(9)$ & $40(24)$ & $<0.001$ \\
\hline Vasopressin & $30(5)$ & $18(4)$ & $12(7)$ & 0.215 \\
\hline Norepinephrine & $15(3)$ & $11(3)$ & $4(2)$ & 1.000 \\
\hline \multicolumn{5}{|l|}{ Vasodilators } \\
\hline Sildenafil & $126(22)$ & $81(20)$ & $45(27)$ & 0.076 \\
\hline Prostaglandin E1 & $37(6)$ & $19(5)$ & $18(11)$ & 0.014 \\
\hline Inhaled Prostacyclin & $19(3)$ & $9(2)$ & $10(6)$ & 0.036 \\
\hline IV Prostacyclin & $19(3)$ & $7(2)$ & $12(7)$ & 0.003 \\
\hline Bosentan & $12(2)$ & $7(2)$ & $5(3)$ & 0.346 \\
\hline ECMO & $186(33)$ & $95(23)$ & $91(54)$ & $<0.001$ \\
\hline Total days on ECMO & $11(7,18)$ & $9(6,14)$ & $14(9,21)$ & $<0.001$ \\
\hline VV & $42(7)$ & $22(5)$ & $20(12)$ & 0.012 \\
\hline VA & $140(24)$ & $72(18)$ & $68(41)$ & $<0.001$ \\
\hline$V V-V A$ & $7(1.2)$ & $2(0.5)$ & $5(3.0)$ & 0.025 \\
\hline
\end{tabular}

Abbreviations: $\mathrm{CDH}$, congenital diaphragmatic hernia; ECMO, extracorporeal membrane oxygenation; VA, venoarterial; VV, venovenous; VV-VA, venovenous converted to venoarterial.

Note: Data presented are $n(\%)$ or median (interquartile range).

\section{Acknowledgements}

The CHNC (http://www.thechnc.org) has partnered with Children's Hospital Association, Inc. (Overland Park, KS; Alexandria, VA) in order to design, launch, and maintain the CHND. We are indebted to the following institutions that serve infants and their families, and also have invested in and continue to participate in the CHND. For more information about CHND, please contact Kate Conrad, Vice President (chnd@childrenshospitals.org). We also thank the site sponsors for the CHND for their investments in this program. The site sponsors for the CHND are as follows:

1. Children's Healthcare of Atlanta at Egleston, Atlanta, GA (Francine Dykes, Anthony Piazza).
2. Children's Healthcare of Atlanta at Scottish Rite, Atlanta, GA (Gregory Sysyn).

3. Children's of Alabama, Birmingham, AL (Carl Coghill).

4. Le Bonheur Children's Hospital, Memphis, TN (Ramasubbareddy Dhanireddy).

5. Boston Children's Hospital, Boston, MA (Anne Hansen).

6. Ann \& Robert H. Lurie Children's Hospital of Chicago, Chicago, IL (Karna Murthy).

7. Nationwide Children's Hospital, Columbus, OH (Kristina Reber).

8. Children's Medical Center Dallas, Dallas, TX (Rashmin Savani).

9. Children's Hospital Colorado, Aurora, CO (Theresa Grover). 
10. Children's Hospital of Michigan, Detroit, MI (Girija Natarajan).

11. Cook Children's Medical Center, Fort Worth, TX (Jonathan Nedrelow, Annie Chi).

12. Texas Children's Hospital, Houston, TX (Stephen Welty).

13. Children's Mercy Hospitals \& Clinics, Kansas City, MO (Eugenia Pallotto).

14. Arkansas Children's Hospital, Little Rock, AR (Becky Rodgers, Robert Lyle).

15. Children's Hospital Los Angeles, Los Angeles, CA (Lisa Kelly [deceased], Steven Chin).

16. UCSF Benioff Children's Hospital Oakland, Oakland, CA (David Durand, Jeanette Asselin, Priscilla Joe).

17. The Children's Hospital of Philadelphia, Philadelphia, PA (Jacquelyn Evans, MichaelPadula).

18. Children's Hospital of Pittsburgh of UPMC, Pittsburgh, PA (Beverly Brozanski).

19. St. Louis Children's Hospital, St Louis, MO (Joan Rosenbaum, Tasmin Najaf, Amit Mathur, Rakesh Rao).

20. All Children's Hospital, St. Petersburg, FL (Victor McKay).

21. Rady Children's Hospital San Diego, San Diego, CA (Mark Speziale).

22. Children's National Medical Center, Washington, DC (Billie Short).

23. Alfred I. duPont Hospital for Children, Wilmington, DE (Kevin Sullivan).

24. Primary Children's Hospital, Salt Lake City, UT (Donald Null, Robert DiGeronimo).

25. Children's Hospital of Wisconsin, Milwaukee, WI (Michael Uhing).

26. Children's Hospital and Medical Center, Omaha, NE (Lynne Willett, John Grebe).

27. Florida Hospital for Children, Orlando, FL (Rajan Wadhawan).

\section{References}

1 Langham MR Jr, Kays DW, Ledbetter DJ, Frentzen B, Sanford LL, Richards DS. Congenital diaphragmatic hernia. Epidemiology and outcome. Clin Perinatol 1996;23(4):671-688

2 Bohn D. Congenital diaphragmatic hernia. Am J Respir Crit Care Med 2002;166(7):911-915

3 Keijzer R, Puri P. Congenital diaphragmatic hernia. Semin Pediatr Surg 2010;19(3):180-185

4 Wynn J, Krishnan U, Aspelund G, et al. Outcomes of congenital diaphragmatic hernia in the modern era of management. J Pediatr 2013;163(1):114-9.e1

5 Tsao K, Lally KP The Congenital Diaphragmatic Hernia Study Group. a voluntary international registry. Semin Pediatr Surg 2008;17(2):90-97

6 Skarsgard ED. Networks in Canadian paediatric surgery: Time to get connected. Paediatr Child Health (Oxford) 2006;11(1):15-18

7 Harting MT, Lally KP. The Congenital Diaphragmatic Hernia Study Group registry update. Semin Fetal Neonatal Med 2014;19(6): 370-375
8 Brindle ME, Cook EF, Tibboel D, Lally PA, Lally KP; Congenital Diaphragmatic Hernia Study Group. A clinical prediction rule for the severity of congenital diaphragmatic hernias in newborns. Pediatrics 2014;134(2):e413-e419

9 Skari H, Bjornland K, Haugen G, Egeland T, Emblem R. Congenital diaphragmatic hernia: a meta-analysis of mortality factors. J Pediatr Surg 2000;35(8):1187-1197

10 Schultz CM, DiGeronimo RJ, Yoder BA; Congenital Diaphragmatic Hernia Study Group. Congenital diaphragmatic hernia: a simplified postnatal predictor of outcome. J Pediatr Surg 2007;42(3): 510-516

11 Congenital Diaphragmatic Hernia Study Group. Estimating disease severity of congenital diaphragmatic hernia in the first 5 minutes of life. J Pediatr Surg 2001;36(1):141-145

12 Baird R, Eeson G, Safavi A, Puligandla P, Laberge JM, Skarsgard ED; Canadian Pediatric Surgery Network. Institutional practice and outcome variation in the management of congenital diaphragmatic hernia and gastroschisis in Canada: a report from the Canadian Pediatric Surgery Network. J Pediatr Surg 2011;46(5): 801-807

13 Murthy K, Dykes FD, Padula MA, et al. The Children's Hospitals Neonatal Database: an overview of patient complexity, outcomes and variation in care. J Perinatol 2014;34(8):582-586

14 American Academy of Pediatrics Committee on Fetus And Newborn. Levels of neonatal care. Pediatrics 2012;130(3):587-597

15 Van Meurs K, Lally KP, Peek G, Zwischenberger JB, eds. ECMO Extracorporeal Cardiopulmonary Support in Critical Care. In: Extracorporeal Life Support Organization (ELSO) 3rd ed. Ann Arbor, MI2005

16 Olsen IE, Groveman SA, Lawson ML, Clark RH, Zemel BS. New intrauterine growth curves based on United States data. Pediatrics 2010;125(2):e214-e224

17 Tsao K, Allison ND, Harting MT, Lally PA, Lally KP. Congenital diaphragmatic hernia in the preterm infant. Surgery 2010;148(2): 404-410

18 Levison J, Halliday R, Holland AJ, et al; Neonatal Intensive Care Units Study of the NSW Pregnancy and Newborn Services Network. A population-based study of congenital diaphragmatic hernia outcome in New South Wales and the Australian Capital Territory, Australia, 1992-2001. J Pediatr Surg 2006;41(6): 1049-1053

19 Jaffray B, MacKinlay GA. Real and apparent mortality from congenital diaphragmatic hernia. Br J Surg 1996;83(1):79-82

20 Harrison MR, Bjordal RI, Langmark F, Knutrud O. Congenital diaphragmatic hernia: the hidden mortality. J Pediatr Surg 1978;13(3):227-230

21 Campbell BT, Herbst KW, Briden KE, Neff S, Ruscher KA, Hagadorn JI. Inhaled nitric oxide use in neonates with congenital diaphragmatic hernia. Pediatrics 2014;134(2):e420-e426

22 Hunter L, Richens T, Davis C, Walker G, Simpson JH. Sildenafil use in congenital diaphragmatic hernia. Arch Dis Child Fetal Neonatal Ed 2009;94(6):F467

23 Su W, Berry M, Puligandla PS, Aspirot A, Flageole H, Laberge JM. Predictors of gastroesophageal reflux in neonates with congenital diaphragmatic hernia. J Pediatr Surg 2007;42(10):1639-1643

24 Clark RH, Kueser TJ, Walker MW, et al; Clinical Inhaled Nitric Oxide Research Group. Low-dose nitric oxide therapy for persistent pulmonary hypertension of the newborn. N Engl J Med 2000; 342(7):469-474

25 The Neonatal Inhaled Nitric Oxide Study Group (NINOS). Inhaled nitric oxide and hypoxic respiratory failure in infants with congenital diaphragmatic hernia. Pediatrics 1997;99(6):838-845

26 Porta NF, Steinhorn RH. Pulmonary vasodilator therapy in the NICU: inhaled nitric oxide, sildenafil, and other pulmonary vasodilating agents. Clin Perinatol 2012;39(1):149-164 